\title{
POLA ASUH ORANGTUA DAN KECENDERUNGAN ADIKSI ONLINE GAME PADA REMAJA AKHIR DI JAKARTA
}

\section{Parenting Style and Online Game Addiction of Late Adolescents in Jakarta}

\author{
Yosephine $^{1)}$, Teguh Lesmana ${ }^{2)}$ \\ 1), 2)Program Studi Psikologi, Universitas Bunda Mulia
}

Diterima 01 September 2020 / Disetujui 10 September 2020

\begin{abstract}
The development of technology has positive and negative impacts on its users. One of the negative impacts caused is the tendency to be addicted from playing online games. The purpose of this study to determine the correlation between parenting with teenagers' tendency of online games addiction in Jakarta. The type of research used is correlational research with quantitative methods using non random sampling method which use Purposive sampling. Correlational research was conducted to determine the relationship of parenting with the tendency of late adolescent online game addiction (18-21 years) in Jakarta. In collecting research data, researchers used the The Development of Indonesian Online Game Addiction Questionnaire developed by Jap et al. and the Construction and Validation of PS-FFQ (Parenting Style Four Factor Questionnaire) developed by Shyny. The results showed a positive relationship between parenting with the tendency of online game addiction in adolescent in Jakarta. So the higher the parenting style, the higher the tendency of online game addiction that he feels. Correlation test results between each dimension of parenting with the tendency of online game addiction, there is only an authoritative dimension that shows no correlation with the tendency of online game addiction. While the correlation test results with authoritarian, neglect, and permissive dimensions have a positive relationship with the tendency of online game addiction.
\end{abstract}

Keywords: Adolescent, Parenting, Tendency to addiction to online games

\begin{abstract}
ABSTRAK
Perkembangan teknologi memberikan dampak positif dan negatif terhadap penggunanya. Salah satu dampak negatif yang ditimbulkan adalah munculnya perilaku bermain online game sampai kecenderungan kecanduan. Tujuan penelitian ini bertujuan untuk mengetahui hubungan pola asuh orangtua dengan kecenderungan adiksi online game remaja akhir di Jakarta. Jenis penelitian yang digunakan adalah adalah penelitian korelasional dengan metode kuantitatif dengan menggunakan teknik non random sampling dengan jenis adalah Purposive sampling. Penelitian korelasional dilakukan untuk mengetahui hubungan pola asuh orangtua dengan kecenderungan adiksi online game remaja akhir (18-21 tahun) di Jakarta. Pada pengumpulan data penelitian, peneliti mengunakan kuesioner The Development of Indonesian Online Game Addiction Questionnaire yang dikembangkan oleh Jap et al. dan Construction and Validation of PS-FFQ (Parenting Style Four Factor Questionnaire) yang dikembangkan oleh Shyny. Hasil penelitian menunjukkan terdapat hubungan positif antara pola asuh orangtua dengan kecenderungan adiksi online game pada remaja akhir berdomisili di Jakarta. Jadi semakin tinggi pola asuh orangtua, maka semakin tinggi kecenderungan adiksi online game yang ia rasakan. Hasil uji korelasi antara setiap dimensi pola asuh orangtua dengan kecenderungan adiksi online game, hanya ada dimensi authoritative yang menunjukkan tidak ada hubungan dengan kecenderungan adiksi online game. Sedangkan hasil uji korelasi dengan dimensi authoritarian, neglect, dan permissive terdapat hubungan positif dan ada hubungan dengan kecenderungan adiksi online game
\end{abstract}

Kata Kunci: Remaja Akhir,Pola Asuh Orangtua,Kecenderungan adiksi online game.

\section{PENDAHULUAN}

Kemajuan teknologi saat ini membuat semua pekerjaan yang dilakukan oleh manusia menjadi lebih mudah dan cepat. Manusia dituntut untuk ikut berkembang dalam

\footnotetext{
*Korespondensi Penulis:

ignatia.yosephine@gmail.com

tlesmana@bundamulia.ac.id
}

kemajuan teknologi. Kemajuan teknologi saat ini dapat ditemui pada segala kegiatan manusia termasuk dalam kegiatan bermain. Permainan dalam bentuk digital atau game sangat diminati oleh senua kalangan, baik anak-anak hingga orang dewasa. Semakin 
berkembangnya kecanggihan teknologi akan menjadi salah satu faktor utama pada perkembangan suatu online game di era globalisasi ini.

Menurut Maulida (2018), hasil studi menunjukkan bahwa mayoritas aktivitas yang dilakukan masyarakat melalui smartphone yang bermain game (25\%). Mereka rata-rata bermain mobile game dengan durasi 53 menit. Aktivitas yang dilakukan pengguna smartphone yaitu menggunakan media sosial (17\%), streaming video (12\%), browsing (10\%), hingga berbelanja online (7\%). Dari sisi usia, gamer di Indonesia tak hanya digandrungi oleh kalangan muda saja. Studi menunjukkan seperempat dari jumlah total gamer memiliki usia 16-24 tahun dan 25-34 tahun, di mana persentasenya masing-masing $27 \%$. Selain itu $24 \%$ lainnya tercatat berusia 35-44 tahun. Pengguna smartphone dengan usia 45-54 tahun juga turut aktif memainkan mobile game dengan persentase $17 \%$ dari basis gamer di Indonesia.

Banyak kasus orang muda tewas karena kelelahan bermain game. Di Amerika Serikat, (Jaya, 2018) ayah tiga anak yang berusia 35 tahun, tewas setelah main game 22 jam tanpa henti. Pria 20 tahun di Republik Rakyat Tiongkok tewas setelah bermain game King of Glory, sembilan jam setiap hari selama lima bulan. Kecanduan game juga memicu tindakan kriminal. Di Desa Terusan, Kecamatan Gedek, Kabupaten Mojokerto, remaja yang baru lulus SMA berusia 18 tahun itu meninggal dunia. Karena tengah asik bermain online game di warung internet yang disebabkan karena kelelahan setelah berimain game selama dua jam. Berselang dua jam kemudian, korban mendadak kejang-kejang di kursi warung internet dengan kondisi komputer menyala (Budianto, 2016).

Badan Kesehatan Dunia World Health Organization (WHO) (2018), memasukan kecanduan game ke dalam daftar penyakit dalam laporan International Classification of Diseases edisi 11 (ICD-11). Kecanduan game resmi masuk sebagai gangguan kesehatan jiwa, gangguan ini dinamai gaming disorder.
Dari Kementrian Kesehatan Republik Indonesia (2018), Seseorang dapat diduga mengalami online / video gaming disorder bila memenuhi kriteria yang telah ditetapkan WHO, yaitu adanya perilaku berpola dengan karakteristik sebagai berikut: (1) ada ganguan kontrol untuk melakukan permainan tersebut (tidak dapat mengendalikan diri); (2) lebih memprioritaskan memainkan permainan tersebut dibandingkan dengan aktivitas yang seharusnya lebih diutamakan; (3) intensitasnya semakin meningkat dan berkelanjutan meskipun ada konsekuensi atau dampak negatif yang dirasakan; (4) perilaku berpola tersebut menyebabkan gangguan yang bermakna pada fungsi pribadi, keluarga, sosial, pendidikan dan area penting lainnya; serta (5) pola tersebut sudah belangsung selama 12 bulan.

Menurut Jap et al. (2013) belum ada kesepakatan mengenai kriteria kecanduan game, sehingga dibuat kriteria sendiri untuk Indonesia berdasarkan teori kecanduan game dan kriteria diagnosis dari kecanduan judi. Dan menggelar focus group discussion dengan tiga psikolog klinis berlisensi dan dapat disimpulkan bahwa orang yang bermain game selama 4-5 hari per minggu dan setiap harinya bermain lebih dari 4 jam maka mungkin terindikasi adiksi. Dengan kriteria tersebut, menemukan 150 siswa $(10,2 \%)$ dari 1477 siswa yang mungkin mengalami adiksi. Lalu, dengan analisis statistik, di dapatkan 89 $(59,3 \%)$ dari 150 siswa yang mungkin mengalami adiksi tersebut dapat dikategorikan mengalami adiksi parah, dan sisanya mungkin dapat masuk kategori adiksi ringan. Maka, dapat diperkirakan prevalensi orang yang mengalami kecanduan game di antara pemain game adalah sekitar $6,1 \%$ di Indonesia.

Menurut Rachmawati (2018), jumlah gamer di Indonesia saat ini diprediksi sudah mencapai 34 juta orang. Dari jumlah tersebut, 19,9 juta diantaranya adalah online gamer berbayar dan rata-rata pengeluarannya mencapai 9,12 dolar Amerika Serikat (AS). Menurut Nurfadilah (2018) ada lebih dari 60 
juta gamers, segmen mobile gaming di Indonesia mengalami pertumbuhan yang amat pesat dan diperkirakan menyentuh setidaknya 100 juta mobile gamers pada 2019-2020. Basis gamers di Indonesia terdiri dari $49 \%$ pengguna ponsel laki-laki dan $51 \%$ pengguna ponsel perempuan.

Menurut Wisnubrata (2018), Setiap benda atau hal-hal yang membuat kita merasa senang akan merangsang otak menghasilkan dopamin, hormon pembuat bahagia, sama halnya seperti ketika bermain game menghasilkan dopamin. Menurut praktisi kesehatan jiwa, pada orang yang gemar bermain game, neurotransmitter dopamin akan meningkat saat ia bermain, sehingga menimbulkan rasa senang (pleasure effect). Manusia dilahirkan dengan dopamin yang rendah, akan selalu mencari cara, benda atau kegiatan yang bisa meningkatkan dopaminnya. Maka dari segi biologi, seseorang yang memiliki gangguan neurotransmitter dopamin, akan lebih rentan mengalami kecanduan. Dalam permainan berbasis online seringkali disuguhkan kontenkonten yang memacu adrenalin pemainnya. Selain itu, terdapat tantangan yang senantiasa bertambah di setiap level permainan. Hal ini tentu menjadi daya tarik sekaligus merupakan risiko bagi orang-orang yang pada dasarnya secara psikologi senang mencari tantangan novelty seeking (Riyani, 2018).

Rossa (2019) mengatakan, Generasi milenial lebih terpengaruh dengan keberadaan gadget karena melihat orangtuanya sibuk mengusap layar ponsel. Anak kian mahir mencari alasan supaya bisa berinteraksi dengan gamer lain di luar sana. Menurut Taruna (2019), Anak dari pasangan orangtua yang tidak akur menjadi penyebab dari kecanduan game ini. Anak akan merasa kesepian dan beralih ke dunia maya. Di sana, mereka mendapat perhatian dan apresiasi lebih karena berkomunikasi dengan pemain lain. Mengalihkan pandangan ke layar handphone sangatlah mudah, tetapi sulit rasanya mengembalikan jati diri anak ke dunia nyata.
Hoskins (2014) menemukan bahwa pola asuh yang melibatkan orangtua akan meningkatkan hubungan yang kuat, aktif dan sehat dalam keluarga. Bukti kuat menunjukkan bahwa orangtua memainkan peran kunci dalam kesuksesan menuju masa remaja. Penelitian yang dilakukan oleh Bibi et al. (2013) menemukan bahwa pola asuh merupakan faktor signifikan dalam perkembangan psikososial anak dan remaja. Sementara itu penelitian yang dilakukan oleh Barry, Frick, \& Grafeman (2008) mengatakan hubungan antara pola asuh tingkat pelanggaran yang dilakukan remaja dan anakanak tergantung pada pola asuh yang dijalankan orangtua.

Dalam Prastyo, Eosina dan Fatimah (2017), Kriteria kecanduan online game ini merupakan pengukuran untuk mengetahui kecanduan atau tidaknya seseorang pemain online game yang ditetapkan pemain yang mendapatkan empat dari tujuh kriteria merupakan indikasi pemain yang mengalami kecanduan online game. Seseorang yang mengalami kecanduan online game akan mengalami beberapa gejala seperti, salience (berpikir tentang bermain online game sepanjang hari), tolerance (waktu bermain online game yang semakin meningkat), mood modification (bermain online game untuk melarikan diri dari masalah), relapse (kecenderungan untuk bermain online game kembali setelah lama tidak bermain), withdrawal (merasa buruk jika tidak dapat bermain online game), conflict (bertengkar dengan orang lain karena bermain online game secara berlebihan), dan problems (mengabaikan kegitan lainnya sehingga menyebabkan permasalahan. Menurut (Arshi 2017) efek negatif bermain online game pada remaja, diantaranya meningkatkan perilaku agresif, isolasi sosial, mengajarkan nilai yang salah, kinerja akademis yang buruk, dan efek buruk.

Berdasarkan permasalahan di atas, maka tujuan penelitian ini adalah untuk mengetahui hubungan pola pengasuh 
orangtua terhadap kecanduan online game pada remaja.da kesehatan.

\section{Pola Asuh Orangtua}

Pola asuh orangtua menurut Baumrind (dalam Santrock, 2010) terdapat empat macam yaitu: (1) pola asuh autoritarian, (2) pola asuh authoritatif, (3) pola asuh permisiftidak peduli, (4) pola asuh permisifmemanjakan. Pola asuh autoritarian cenderung menetapkan standar yang mutlak harus dituruti, biasanya dibarengi dengan ancaman-ancaman. Hal ini sesuai dengan yang dikemukakan oleh Santrock (2010), pola pengasuhan ini cenderung bersifat membatasi dan menghukum serta mendesak remaja untuk mengikuti petunjuk orangtua. Mereka mengontrol dan menghukum anak, perkataan mereka merupakan peraturan yang harus ditaati oleh anak-anak mereka. Apabila anak tidak mau melakukan apa yang dikatakan oleh orangtua, maka orangtua tipe ini tidak segan untuk menghukum anak.

Pola asuh autoritatif adalah pola asuh yang tidak kaku dengan penuh kehangatan dan memberikan kebebasan kepada anak, akan tetapi orangtua tetap mengendalikam perilaku anak (Greening, Stoppelbein \& Luebbe, 2010). Mereka mendorong remaja untuk bebas tetapi tetap memberikan batasan dan mengendalikan tindakan mereka (Santrock, 2010). Orangtua dengan pola asuh ini bersikap rasional, selalu mendasari tindakannya pada rasio atau pemikiranpemikiran. Mereka mencoba untuk selalu memberikan alasan dan penjelasan mengenai sikap anak yang seharusnya ditampilkan dalam kehidupan sehari-hari kepada anakanak mereka. Mereka juga secara rasional memberikan penjelasan mengenai hukuman yang mereka berikan kepada anak anak (Feldman,2011).

Dalam pola asuh permisif-tidak peduli, orangtua memberikan pengawasan yang sangat longgar. Orangtua sangat tidak ikut campur dalam kehidupan remaja. Orangtua memberikan kesempatan pada anaknya untuk melakukan sesuatu tanpa pengawasan yang cukup darinya. Menurut Jacobson \& Crockett (dalam Santrock, 2010) di satu sisi, pengawasan orangtua berhubungan dengan kelas yang lebih tinggi, aktivitas seksual yang lebih rendah, dan lebih sedikit remaja yang depresi. Orangtua dengan pola asuh ini cenderung tidak konsisten dalam memberikan umpan balik (feedback) kepada anak.

Pola asuh permisif-memanjakan adalah suatu pola asuh di mana orangtua sangat terlibat dengan remaja, tetapi sedikit sekali menuntut atau mengendalikan mereka. Orangtua yang bersifat permisif-memanjakan, mengizinkan remaja melakukan apa saja yang mereka inginkan. Hal tersebut mengakibatkan remaja tidak pernah belajar bagaima mengendalikan perilakunya. Remaja selalu berharap mereka bisa mendapatkan semua yang mereka inginkan. Beberapa orangtua yang memperlakukan anak remaja secara demikian, karena mereka percaya bahwa kombinasi keterlibatan akan menghasilkan remaja yang kreatif dan percaya diri (Santrock, 2010).

\section{Adiksi Online game}

Adiksi adalah suatu keterlibatan secara terus-menerus dengan sebuah aktivitas meskipun hal-hal tersebut mengakibatkan konsekuensi negatif. Kenikmatan dan kepuasanlah yang pada awalnya dicari, namun perlu keterlibatan dalam beberapa waktu dengan aktivitas tersebut agar seseorang merasa normal. Seseorang bisa dikatakan adiksi online game jika penggunanya bisa bermain lebih dari 3 kali dalam sehari (Laili, 2015).

Griffiths (2008) menyebutkan bahwa terdapat 6 kriteria adiksi online game, yaitu : (1) salience, (2) tolerance, (3) mood modification, (4) withdrawal, (5) conflict, (6) relapse. Fase salience terjadi ketika bermain video game menjadi aktivitas paling penting dalam kehidupan seseorang dan mendominasi pemikirannya (keasyikan dan distorsi kognitif), perasaan (mengidam), dan perilaku (kemunduran perilaku yang disosialisasikan).

Fase Tolerance adalah proses dimana peningkatan jumlah bermain video game diperlukan untuk mencapai efek pengubah suasana hati sebelumnya. Ini pada dasarnya berarti bahwa untuk orangorang yang terlibat dalam permainan video game, mereka secara bertahap membangun jumlah waktu yang 
mereka habiskan untuk terlibat dalam perilaku (Griffiths, 2008).

Fase Mood modification mengacu pada pengalaman subjektif yang dilaporkan orang sebagai konsekuensi dari terlibat dalam permainan video game dan dapat dilihat sebagai strategi kopint (yaitu, mereka mengalami "gebrakan" yang membangkitkan dari "pelarian" atau "melarikan diri).

Fase Withdrawal adalah keadaan perasaan yang tidak menyenangkan atau efek fisik yang terjadi ketika permainan video game dihentikan atau tiba-tiba berkurang, misalnya getar, kemurungan, lekas marah, dan sebagainya (Griffiths, 2008).

Fase Conflict merujuk pada konflik antara pemain video game ada orang-orang di sekitar mereka (konflik antar pribadi), konflik dengan yang lain kegiatan (pekerjaan, pekerjaan sekolah, kehidupan sosial, hobi, dan minat) atau dari dalam individu itu sendiri (konflik intrapsik dan/atau perasaan kehilangan kontrol yang subjektif) yang berkaitan dengan menghabiskan terlalu banyak waktu untuk bermain video game (Griffiths, 2008).

Fase Relapse adalah kecenderungan untuk berulang kembali ke pola-pola sebelumnya dari permainan video game untuk kambuh dan bahkan untuk pola-pola yang paling ekstrem khas dari ketinggian permainan video game yang berlebihan harus segera di pulihkan setelah periode pantang atau kontrol (Griffiths, 2008).

\section{METODE PENELITIAN}

\section{Desain Penelitian}

Penelitian ini merupakan penelitian kuantitatif yang menggunakan teknik korelasional. Penelitian korelasional adalah penelitian yang di rancang untuk menentukan tingkat hubungan antara dua sifat perilaku, atau peristiwa (Myers \& Hansen, 2012).

\section{Teknik Sampling dan Kriteria Subjek}

Teknik sampling dalam penelitian ini adalah purposive random sampling, di mana merupakan pengambilan sampel yang didasarkan pada tujuan tertenntu. Teknik ini mengambil subjek dengan pertimbangan dan kriteria untuk memenuhi tujuan penelitian. Kriteria sampel dalam penelitian ini : (a) usia 18-21 tahun, (b) jenis kelamin laki-laki atau perempuan, (c) bermain online game baik melalui komputer/PC dan handphone, (d) bermain online game dengan minimal bermain online game secara teratur selama 45 hari seminggu dan rata-rata menghabiskan lebih dari 4 jam setiap hari, (e) domisili di Jakarta.

\section{Teknik Pengumpulan Data}

Teknik pengumpulan data yang digunakan berupa kuesioner. Alat ukur yang digunakan untuk mengukur variable terdiri atas: (a) skala The Development of Indonesian Online Game Addiction Questionnaire yang dikembangkan oleh Jap et al. (2013) untuk mengukur kecenderungan adiksi online game, dan Construction and Validation of PS-FFQ (Parenting Style Four Factor Questionnaire) yang dikembangkan oleh Shyny (2017) untuk mengukur 4 kecenderungan tipe pola asuh.

\section{Reliabilitas Alat Ukur}

Peneliti menguji reliabilitas alat ukur dengan menggunakan 30 sampel remaja akhir di Jakarta. Berdasarkan hasil uji reliabilitas ditemukan bahwa reliabilitas dari alat ukur Construction and Validation of PS-FFQ (Parenting Style Four Factor Questionnaire) memiliki reliabilitas yang cukup baik dengan reliabilitas setiap dimensi adalah 0.755 untuk dimensi autoritarian, 0.716 untuk dimensi autoritatif, 0.625 untuk dimensi permisiftidak peduli, dan 0.738 pada dimensi permisif-memanjakan. Sedangkan reliabilitas alat ukur The Development of Indonesian Online Game Addiction Questionnaire memiliki reliabilitas 0.706 .

\section{Validitas Alat Ukur}


Pada penelitian ini peneliti menguji validitas instrumen Construction and Validation of PS-FFQ (Parenting Style Four Factor Questionnaire) dan instrumen The Development of Indonesian Online Game Addiction Questionnaire dengan menggunakan Face Validity. Face Validity merupakan langkah telaah dan revisi butir dari pernyataan berdasarkan pendapat profesional (Professional Judgement) para penelaah (Sugiyono, 2013).

Peneliti menguji validitas dari alat ukur Construction and Validation of $P S-F F Q$ (Parenting Style Four Factor Questionnaire) dimana alat ukur ini diadaptasi ke bahasa Indonesia serta dimodifikasi agar sesuai dengan konteks pada remaja akhir di Jakarta, lalu peneliti melibatkan penerjemah pada Lembaga Media Multi Bahasa untuk mengecek kesesuaian hasil terjemahan dengan bahasa aslinya. Tahap selanjutnya, peneliti melibatkan para ahli dibidang psikologi untuk menilai kesesuaian terjemahan butir dengan konteks yang akan dipakai dalam penelitian.

\section{HASIL DAN PEMBAHASAN}

\section{Gambaran Umum Responden Penelitian}

Responden yang terlibat dalam penelitian ini berasal dari para pemain online game yang terdiri dari berbagai jenis usia, jenis kelamin, domisili, lama waktu bermain game, pendidikan kedua orangtua. Responden yang didapatkan berjumlah 263 responden yang telah mengisi kuesioner dengan lengkap dan sesuai dengan kriteria yang telah ditentukan oleh peneliti.
Tabel 1

Gambaran Demografis Subjek

\begin{tabular}{lcc}
\hline & Jumlah & Persentase \\
\hline Gender & & \\
Laki-laki & 143 & $54.4 \%$ \\
Perempuan & 120 & $45.6 \%$
\end{tabular}

Usia

18

$42 \quad 16 \%$

19

$69 \quad 26.2 \%$

20

$37 \quad 14.1 \%$

21

$115 \quad 43.7 \%$

Domisili

$\begin{array}{lll}\text { Jakarta Utara } & 98 & 37.3 \% \\ \text { Jakarta Pusat } & 32 & 12.2 \% \\ \text { Jakarta Barat } & 70 & 26.6 \% \\ \text { Jakarta Selatan } & 18 & 6.8 \% \\ \text { Jakarta Timur } & 45 & 17.1 \%\end{array}$

Waktu Lama Bermain

$<10$ jam / minggu $\quad 127 \quad 48.3 \%$

$<20$ jam / minggu $\quad 68 \quad 25.9 \%$

$<30 \mathrm{jam} /$ minggu $\quad 37 \quad 14.1 \%$

$>40 \mathrm{jam} /$ minggu $\quad 31 \quad 11.8 \%$

Pendidikan Ayah

$\begin{array}{lll}\text { SD } & 19 & 7.2 \% \\ \text { SMP } & 34 & 12.9 \% \\ \text { SMA } & 119 & 45.2 \% \\ \text { D3 } & 19 & 7.2 \% \\ \text { S1 } & 52 & 19.8 \% \\ \text { S2 } & 15 & 5.7 \% \\ \text { S3 } & 5 & 1.9 \%\end{array}$

Pendidikan Ibu

$\begin{array}{lll}\text { SD } & 22 & 8.4 \% \\ \text { SMP } & 28 & 10.6 \% \\ \text { SMA } & 126 & 47.9 \% \\ \text { D3 } & 33 & 12.5 \% \\ \text { S1 } & 46 & 17.5 \% \\ \text { S2 } & 5 & 1.9 \%\end{array}$


S3 3 $1.1 \%$

\section{Uji Normalitas}

Uji normalitas digunakan untuk mengetahui apakah sebuah data terdistribusi normal atau tidak. Pada penelitian ini, uji normalitas dilakukan dengan metode Kolmogorov-Smirnov dengan menggunakan sistem perhitungan SPSS 23. Hasil uji normalitas pada penelitian ini dapat di lihat pada tabel 2 .

Tabel 2

Uji Normalitas

\begin{tabular}{lc}
\hline \multicolumn{1}{c}{ Alat Ukur } & Sig $(\mathrm{p})$ \\
\hline Autoritarian & .091 \\
Autoritatif & .097 \\
Permisif-tidak peduli & .125 \\
Perfmisif-memanjakan & .099 \\
Adiksi online game & .088 \\
\hline
\end{tabular}

Data dapat dikatakan normal apabila signifikansi berskor lebih dari 0.05 ( $\mathrm{P}>0.05)$. Dalam penelitian ini diperoleh hasil uji normalitas di mana penyebaran data tidak normal.

\section{Uji Korelasi}

Pada uji korelasi dengan kecenderungan adiksi online game dilakukan pada setiap dimensi pada pola asuh orangtua yaitu autoritarian, autoritatif, permisif-tidak peduli, dan permisif-memanjakan.

Tabel 3

Uji Korelasi

\begin{tabular}{lr}
\hline Pola Asuh & $\begin{array}{r}\text { Adiksi Online } \\
\text { game }\end{array}$ \\
\hline Autoritarian & $.328^{* *}$ \\
Autoritatif & .000 \\
Permisif-tidak peduli & $.175^{* *}$ \\
Perfmisif-memanjakan & $.284^{* *}$ \\
\hline **Korelasi signifikan $<0.01$ &
\end{tabular}

Berdasarkan hasil uji coba korelasi di atas, dapat dilihat bahwa pada dimensi autoritarian diperoleh hasil korelasi koefisien sebesar 0.328 dengan signifikansi 0.000 yang artinya ada hubungan yang signifikan diantara autoritarian dengan kecenderungan adiksi online game $(\mathrm{p}<0.01)$. Pada dimensi autoritatif diperoleh hasil korelasi koefisien sebesar 0.000 dengan signifikansi 0.996 menunjukkan bahwa tidak ada hubungan yang signifikan antara autoritatif dengan kecenderungan adiksi online game ( $\mathrm{p}>0.05)$. Kemudian pada dimensi permisif-tidak peduli diperoleh hasil korelasi koefisien sebesar 0.175 dengan signifikansi 0.004 menunjukkan bahwa adanya hubungan antara permisif-tidak peduli dengan kecenderungan adiksi online game $(\mathrm{p}<0.01)$. Selanjutnya, pada dimensi permisif-memanjakan korelasi koefisien sebesar 0.284 dengan signifikansi 0.000 menunjukkan bahwa adanya hubungan antara permisif-memanjakan dengan kecenderungan adiksi online game $(\mathrm{p}<0.01)$. Ketiga dimensi pola asuh orangtua yang memiliki hubungan signifikan memiliki tipe korelasi positif, yang dapat diartikan jika skor dimensi pola asuh orangtua meningkat maka kecenderungan adiksi online game juga meningkat, begitu juga sebaliknya.

\section{Pembahasan}

Hasil uji korelasi antara dimensidimensi pola asuh orangtua dengan kecenderungan adiksi online game menunjukkan bahwa pada dimensi autoritarian memiliki hubungan yang signifikan dengan kecenderungan adiksi online game yang memiliki nilai korelasi sebesar 0.328 yang artinya apabila seseorang yang di asuh dengan pola asuh autoritarian mempengaruhi kecenderungan adiksi online game. Hasil penelitian ini serupa dengan Sugiyatno (2009) ditemukan remaja yang mendapat gaya pengasuhan autoritarian pada taraf sedang, dimana hasil penelitian menunjukkan bahwa ada korelasi positif yang signifikan antara pola asuh autoritarian orangtua dengan peilaku bermain online game.

Sedangkan, hubungan antara dimensi pola asuh orangtua yaitu authoritatif dengan kecenderungan adiksi online game 
menunjukkan tidak ada hubungan signifikan 0.996 dengan korelasi koefisien sebesar 0.000 . penenlitian ini sejalan dengan Djamarah (2014) mengaatakan bahwa orangtua dengan pola asuh autoritatif bersikap rasional, selalu mendasari tindakan pada rasio atau pemikiran-pemikiran. Orangtua tipe ini bersikap relistis terhadap kemampuan anak, tidak berharap yang berlebihan yang melampaui kemampuan anak. Dalam penelitian lain, menurut Moazedian, et al (2014) di Iran menunjukkan bahwa pola asuh autoritatif berpengaruh rendah kepada permasalahan pengguna internet.

Kemudian, pada hasil uji korelasi dimensi pola asuh orangtua permisif-tidak peduli menunjukkan bahwa terdapat hubungan yang signifikan dengan korelasi koefisiensi sebesar 0.175 bersifat positif. Hal yang sesuai dengan penelitian Anandari (2013) menyatakan bahwa orangtua dengan pola asuh permisif-tidak peduli mempengaruhi anak yang mengalami kecanduan online game.

Pada hasil uji korelasi antara pola asuh orangtua dimensi permisif-memanjakan menunjukkan bahwa terdapat hubungan yang signifikan dengan korelasi koefisien sebesar 0.284. menurut Darling (2014), mengatakan bahwa remaja yang diasuh dengan pola asuh otoriter masih mampu mengontrol diri dibandingkan dengan remaja yang diasuh dengan pola asuh demokratis dan permisif, disebabkan karena adanya pendisiplinan dan pemantauan dari orangtua. Pendisiplinan dan pemantauan dengan cara memenuhi tuntan orangtua agar terhindar dari hukuman. Tetapi kurangnya dukungan dan kehangatan pada anak berdampak pada kurangnya kemampuan sosial anak.

\section{SIMPULAN}

Secara keseluruhan, setiap dimensi pola asuh orangtua dengan kecenderungan adiksi online game memiliki hubungan yang signifikan dan memiliki nilai korelasi yang positif, kecuali untuk dimensi autoritatif yang tidak memiliki hubungan dengan kecenderungan adiksi online game.

Untuk penelitian selanjutnya, diharapkan untuk jumlah sampel yang lebih banyak, pengisian kuesioner yang menggunakan pola asuh orangtua dan kecenderungan adiksi online game sehingga muncul peluang bagi responden untuk faking good dan bias dengan mengisi kuesioner tidak sesuai dengan keadaan dirinya, melainkan agar dipandang baik oleh orang lain. Tentunya mempengaruhi hasil perhitungan statistik lalu komposisi responden yang tidak seimbang karena penyebaran data yang bersifat acak dan tidak merata sehingga data demografi seperti domisili, jenis kelamin, lama waktu bermain online game tidak merata dan semakin sulit untuk melakukan generalisasi karena tidak meratanya penyebaran data.

Maka dari itu peneliti menyarankan untuk penelitian selanjutnya dengan topik serupa agar proporsi responden ditambah. Selain itu agar hasil penelitiannya lebih objektif maka disarankan agar proporsi ditambah seperti kelas, jurusan, jenjang pendidikan diatur sedemikian rupa agar tidak ada data yang menjadi terlalu dominan dan hasil penelitiannya bersifat representatif.

\section{DAFTAR PUSTAKA}

Arshi. (2017, 3 Juli). 5 positive and negative fffects of video games on teenagers. Diakses pada 2017, dari http://www.momjunction.com/articles/effe cts-of-video-games-on-teenagers

Anandari, D.R. (2013). Orangtua dengan pola asuh permisif dan resiko anak kecanduan online game. Surabaya: Universitas Airlangga.

Bibi, F., Chaudhry, A.G., Awan, E.A., \& Tariq, B. (2013). Contribution of parenting style in life domain of children. IOSR Journal of Humanities and Social Science (IOSR-JHSS), 12(2), h.91-95. 
Budianto, E.E. (2016, 9 Agustus). Pemuda di Mojokerto tewas saat main online game, polisi: mungkin kelelahan. Diakses pada 2019, dari https://news.detik.com/berita/ 3271570/ pemuda-di-mojokerto-tewassaat-main-game-online-polisi-mungkinkelelahan

Barry, C.T., Frick, P.J., Grafeman, S.J. (2008). Child versus parent reports of parenting practices: implications for the conceptualization of child behavioral and emotional problems. Assessment, 15(3), h.294-303.

Darling, N. (2014). Parenting style and Its Correlates. ERIC Clearinghouse on Elementary and Early Childhood Education Champaign IL.

Djamarah. (2014). Pola asuh orangtua dan komunikasi dalam keluarga. Jakarta: PT Rineka Cipta.

Feldman, R. S. (2011). Development across the life span. (Ed. Ke-6). New Jersey: Pearson.

Greening, L., Stoppelbein, L, \& Luebbe, A. (2010). The moderating effects of parenting styles on African-American and Caucasian children's suicidal behaviors. Journal of Youth and Adolescence. 39, h.357-369.

Griffiths, M.D. (2008). Diagnosis and management of video game addiction. Diunduh dari https://www.researchgate.net/publication/ 273948544_Diagnosis_and_management_ of_video_game_addiction

Hoskins, D.H. (2014). Consequences of parenting on adolescent outcomes. Societies 4(3), h.506-531.

Jap, T., Triatri, S., Jaya, E.S., \& Suteja, M.S. (2013). The development of Indonesian online game addiction questionnaire. Plos One, 8(4): e61098.

Jaya, E.S. (2018, 4 Juli). WHO Tetapkan Kecanduan game sebagai gangguan mental, bagaimana "gamer" Indonesia bisa sembuh? Diakses pada 2019, dari https://theconversation.com/who-tetapkankecanduan-game-sebagai-gangguan- mental-bagaimana-gamer-indonesia-bisasembuh-99029

Kementrian Kesehatan Republik Indonesia. (2018). Bermain online game: mengisi waktuluang, bersenang-senang atau ketergantungan. Diunduh pada 2019, dari http://www.depkes.go.id/article/view/1807 0600009/bermain-game-online-mengisiwaktu-luang-bersenang-senang-atauketergantungan.html

Laili, F.M. (2015). Penerapan konseling keluarga untuk mengurangi kecanduan online game pada siswa kelas VIII SMP Negeri 21. Jurnal BK Unesa, 5(1), h.6573.

Maulida, L. (2018, 17 Oktober). Jumlah Gamer di Indonesia capai 100 juta di 2020. Diakses pada 2019, dari https://www.tek.id/insight/jumlah-gamerdi-indonesia-capai-100-juta-di-2020b1U7v9c4A

Moazedian, A., Taqavi, S.A., HosseiniAlmadani, S.A., Mohammadyfar, M.A., \& Sabetimani, M. (2014). Parenting style and internet addiction. Journal of Life Sscience and Biomedicine, 4(1), h.914.

Myers, A., \& Hansen, C.H. (2012). Experimental psychology. US: PreMedia Global.

Nurfadilah, P.S. (2018). Ada 60 juta Gamers, Potensi Iklan "mobile game" kurang dilirik

https://ekonomi.kompas.com/read/2018/10 /17/214800126/ada-60-juta-gamerspotensi-iklan-di-game-mobile-kurangdilirik

Papalia, D.E, \& Feldman, R.D. (2012). Experience human development (12th edition). NY: McGraw Hill International Edition.

Prastyo, Y., Eosina,P, \& Fatimah, F. (2017). Pembagian tingkat kecanduan online game menggunakan $k$-means clustering serta korelasinya terhadap prestasi akademik. Elinvo, 2(2), h.138-148.

Rachmawati, A.R. (2019). Gamer di Indonesia diprediksi capai 34 juta orang. 
Versi Online: http://journal.ubm.ac.id/index.php/psibernetika DOI: 10.30813/psibernetika.v13i1.2272

Hasil Penelitian

Diunduh dari https://www.pikiranrakyat.com/ekonomi/2018/08/06/gamerindonesia-diprediksi-capai-34-juta-orang428379

Riyani, U.E. (2018). Ini faktor-faktor yang membuat seseorang mudah kecanduan online game. Diunduh dari https://lifestyle.okezone.com/read/2018/07 /09/481/1919904/ini-faktor-faktor-yangmembuat-seseorang-mudah-kecanduangame-online

Rossa, V. (2019). Lepas dari kecanduan game, andrew ryan samuel jadi motivator. Diunduh dari https://www.suara.com/lifestyle/2019/01/2 8/100115/lepas-dari-kecanduan-gameremaja-16-tahun-jadi-motivator

Santrock, J.W. (2010). Adolescence. NY: Mc Graw Hill

Sugiyatno. E.N. (2009). Hubungan antara pola asuh otoriter dengan perilaku bermain games online pada remaja. Semarang: Perpustakaan Unika.

Sugiyono (2013). Metode penelitian pendidikan pendekatan kuantitatif, kualitatif, dan $R \& D$. Alfabeta: Bandung.

Taruna, B. (2019). Kisah Andrew Ryan, dulu pecandu kini memotivasi penggila online game untuk berhenti. Diunduh dari https://lifestyle.okezone.com/read/2019/01 /28/196/2010148/kisah-andrew-ryan-dulupecandu-kini-memotivasi-penggila-gameonline-untuk-berhenti

Tiwa, J.R, Palandeng, O.I, \& Bawotong, J. (2019). Hubungan pola asuh orangtua dengan kecanduan online game pada anak usia remaja di SMA Kristen Zaitun Manado. Jurnal Keperawatan, 7(1), h.1-7.

WHO. (2018). WHO minta masukan Indonesia soal jaminan kesehatan nasional diunduh dari https://nasional.kompas.com/read/209/10/ 18/21134141/who-minta-masukanindonesia-soal-jaminan-kesehatannasional

Wisnubrata. (2018). Kecanduan game bisa jadi tanda gangguan jiwa. Diunduh dari https://lifestyle.kompas.com/read/2018/02/
Jurnal Psibernetika

Vol.13 (No.1) : 49 -58. Th. 2020

p-ISSN: 1979-3707

e-ISSN: 2581-0871

20/145928020/kecanduan-main-gamebisa-jadi-tanda-gangguan-jiwa?page=all 